Research Paper

\title{
A Sonic Hedgehog-Gli-Bmil signaling pathway plays a critical role in p27 deficiency induced bone anabolism
}

\author{
Jun $\mathrm{Wu}^{1}$, Rong Wang ${ }^{1}$, Xuechun Kan ${ }^{1}$, Jinghan Zhang ${ }^{1}$, Wen Sun ${ }^{1}$, David Goltzman ${ }^{2}$, and Dengshun \\ $\mathrm{Miao}^{1,3 凶}$ \\ 1. State Key Laboratory of Reproductive Medicine; Research Center for Bone and Stem Cells; Department of Anatomy, Histology and Embryology; Key \\ Laboratory for Aging \& Disease; Nanjing Medical University, Nanjing 211166, China. \\ 2. Calcium Research Laboratory, McGill University Health Centre and Department of Medicine, McGill University, Montreal, Quebec H3A 1A1, Canada. \\ 3. The Research Center for Aging, Affiliated Friendship Plastic Surgery Hospital of Nanjing Medical University, Nanjing 210029, China.
}

$\square$ Corresponding author: Dengshun Miao, M. D., Ph. D., State Key Laboratory of Reproductive Medicine, Research Center for Bone and Stem Cells; Department of Anatomy, Histology and Embryology; Key Laboratory for Aging \& Disease; Nanjing Medical University, Nanjing 211166; The People's Republic of China. E-mail: dsmiao@njmu.edu.cn; Tel \& FAX: 011-86-25-8686-9377.

(1) The author(s). This is an open access article distributed under the terms of the Creative Commons Attribution License (https://creativecommons.org/licenses/by/4.0/). See http://ivyspring.com/terms for full terms and conditions.

Received: 2021.08.10; Accepted: 2021.12.07; Published: 2022.01.01

\begin{abstract}
To explore the mechanism of the bone anabolic action of p27 deficiency, we first confirmed that osteoblast formation and osteogenesis were significantly increased in p27 deficient mice compared with their wild-type littermates. Microarray analysis of differential gene expression profiles, followed by real-time RT-PCR and Western blots revealed that p27 deletion significantly upregulated the expression of Sonic hedgehog (Shh), Glil and 2 and their target gene Bmil in bone tissue, and significantly down regulated the expression of the negative regulators of the Shh pathway Sufu, Patched 1 and Gli3 in bone tissue. The Shh antagonist KAAD-cyclopamine or vismodegib significantly reduced osteogenesis of bone marrow mesenchymal stem cells (BM-MSCs) in vitro and osteoblastic bone formation in vivo. The results of chromatin immunoprecipitation and double luciferase assay demonstrated that p27 inhibited Shh transcription mediated via E2F4. Bmil knockout blocked the increase of osteoblastic bone formation induced by $\mathrm{P} 27$ deficiency in vivo. In conclusion, the results of this study indicate that the signaling pathway Shh-Gli-Bmil plays a critical role in p27 deficiency induced bone anabolic action, suggesting that Bmil may be an important therapeutic target for osteoporosis induced by activation of p 27 signaling or inactivation of sonic hedgehog signaling.
\end{abstract}

Key words: p27, osteogenesis, osteoblast formation, sonic hedgehog signaling, Bmi1

\section{Introduction}

The protein p27 (cyclin-dependent kinase inhibitor $1 \mathrm{~B}$ or $\mathrm{p} 2 \mathrm{TK}^{\mathrm{Kip}}$ ) is a member of the Cip/Kip family that also includes $\mathrm{p} 21^{\mathrm{Cip} 1}$ and $\mathrm{p} 57^{\mathrm{Kip} 2}$. Its classical role is to bind and inhibit multiple cyclin-dependent kinases involved in cell cycle progression [1]. The importance of p27 as a cell cycle regulator in vivo was revealed by the main phenotypes of p27-\% mice, namely increased body size, organ hyperplasia, pituitary tumors, and retinal dysplasia [2]. In addition to these phenotypes, some studies have implied that p27 is likely a critical regulator of osteoblastic bone formation and osteogenesis. Bone marrow cells from p27\%-mice exhibited increased proliferative activity and form an increased number and larger size of osteoblastic colonies, which can further differentiate to the stage of mineralization [3]. Our previous studies demonstrated that p27 deletion significantly increased osteoblastic bone formation parameters in both long bones and mandibles, and improved the defective osteoblastic bone formation in 2-week-old mice lacking the nuclear localization sequence and C-terminus of PTH-related protein [4, 5]. However, the detailed mechanism underlying p27 gene action in modulating osteoblastic bone formation is unclear.

Bmi1 (B-lymphoma Mo-MLV insertion region 1) is a key protein partner in Polycomb Repressive Complex 1 (PRC1) and acts as a transcriptional 
repressor of the Ink4a/Arf locus [6]. Bmi1 knockout $\left(\mathrm{Bmi1}^{-/-}\right)$mice, established by homologous gene recombination technology, displayed a premature aging phenotype, which was associated with decreased self-renewal ability of neural stem cells and hematopoietic stem cells [7-9]. Our studies demonstrated that Bmi1/-/- mice exhibited premature osteoporosis associated with reduced mesenchymal stem cell (MSC) self-renewal and decreased ability to differentiate into osteoblasts [10]. We recently reported that overexpression of Bmi1 in MSCs exerts antiaging and antiosteoporosis effects by inactivating p16/p19 signaling and inhibiting oxidative stress [11]. Bmi1 expression levels were up-regulated in bone tissue from p27 deficient mice [4, 5]. However, it is unclear whether Bmi1 mediates p27 deficiencyinduced bone anabolic action and how p27 regulates Bmi1 expression.

Overexpression of Bmi1 promotes cell proliferation and is required for pathway driven tumorigenesis. Bmi1 expression positively correlates with increasing Shh ligand concentrations. Chromatin immunoprecipitation reveals that Gli1 (gliomaassociated oncogene1) preferentially binds to the Bmi1 promoter, and Bmi1 transcript levels are increased and decreased by Gli1 overexpression and downregulation, respectively [12]. There is a potential nexus of Shh-Gli1-Bmi1 cell signaling to promote chemoresistance in glioma [13]. The critical function of Shh signaling in bone formation has been identified in the past two decades. In the early stages of embryonic limb development, Shh acts as a major morphogen in patterning the limb buds [14]. Shh is involved in intramembranous and endochondral ossification during fracture healing [15]. Shh enhances osteogenesis of bone marrow MSCs (BM-MSCs) in vitro and in vivo [16-18]. Previous studies have shown that haplo- or total insufficiency of p27 can induce the expression of Shh and increase the incidence of medulloblastoma [19]; the down-regulation of the p27 gene in parathyroid carcinoma was always accompanied by upregulated Shh and Gli [20]. Emerging evidence indicates that p27 also behaves as a transcriptional regulator. It associates with a number of gene promoters through E2F4/p130 complexes acting as a transcriptional repressor of these genes [2, 21-23]. Therefore, we are investigated whether p27 might be recruited to the Shh promoter region to form $\mathrm{p} 27 / \mathrm{E} 2 \mathrm{~F} 4 / \mathrm{p} 130$ complexes, contributing to the repression of Shh signaling in osteogenic cells, and whether p27 deficiency stimulates osteoblast formation and osteogenesis by activating Shh-Gli-Bmi1 signaling.

To answer these questions, long bone phenotypes of 4-week-old p27 deficient and wild-type mice were compared to determine whether deletion of p27 stimulates osteoblast formation and osteogenesis. Microarray analyses of differential gene expression profiles were performed in long bone extracts from p27-/- mice and their wild-type littermates to identify whether deletion of p27 activates Shh-Gli-Bmi1 signaling. The effects of an Shh antagonist or an Shh agonist on osteogenesis in p27 deficient or overexpressed BM-MSCs in vitro, and the effect of the Shh antagonist on osteoblastic bone formation in p27 deficient mice in vivo were determined to establish whether Shh signaling mediates p27 deficiency-induced osteogenesis and osteoblastic bone formation. We then generated $\mathrm{p} 27^{-/-\mathrm{Bmi1}} / /-$ double knockout mice, and their bone phenotypes were compared with wild-type littermates to determine whether deletion of Bmi1 blocks p27 deficiency-induced osteoblastic bone formation by blocking the Shh signaling pathway.

\section{Methods}

\section{Mice and genotyping}

Two mutant mouse models were used in this study: p27 heterozygous (p27 $\left.7^{+/}\right)$mice were purchased from the Jackson Laboratory (Bar Harbor, ME, USA). Bmi1 heterozygous (Bmi1 ${ }^{+/-}$) mice were generously provided by Dr. Anton Berns, of the Netherlands Cancer Institute. The p27 +/- mice and Bmi1 $1^{+/-}$mice were fertile and were mated to produce offspring heterozygous at both loci, which were then mated to generate $\mathrm{p} 27 \% \mathrm{Bmi1} \%$ pups. All animal experiments were carried out in compliance with, and approval by, the Institutional Animal Care and Use Committee. The genotype of p27\%- and Bmi1 $\%$ mice was confirmed as described previously $[4,24]$.

\section{Microarray analysis and real-time RT-PCR}

RNA was isolated from mouse bone tissue, excluding the growth plate, using Trizol reagent (Invitrogen, Cat\#15596026, Carlsbad, CA, USA) according to the manufacturer's protocol. RNA quality was assessed by Nanodrop ND-1000 and RNA integrity was assessed using standard denaturing agarose gel electrophoresis. The Mouse $12 \times 135 \mathrm{~K}$ gene expression array was manufactured by Roche NimbleGen. The microarray analysis was performed by KangChen Bio-tech. Total RNA was extracted from femurs or BM-MSCs using Trizol reagent (Invitrogen, Cat\#15596026, Carlsbad, CA, USA) according to the manufacturer's protocol. Quantitative real-time RT-PCR amplifications were performed as previously described [5]. Reverse-transcription reactions were performed using the PrimeScript RT Master Mix (Perfect Real Time, Takara Bio Inc., Cat\#RR036D, 
Shiga, Japan). Real-time RT-PCR primers are listed in Table 1.

Table 1. Primers used in this study for real time RT-PCR

\begin{tabular}{|c|c|c|c|c|}
\hline Name & S/AS & Sequence & $\mathrm{Tm}$ & bp \\
\hline \multirow[t]{2}{*}{ p27 } & S & GGGCAGATACGAGTGGCAG & 62 & 153 \\
\hline & AS & TGAGACCCAATTAAAGGCACC & & \\
\hline \multirow[t]{2}{*}{ Bmi-1 } & S & ATCСССАСТTAATGTGTGTCCT & 60 & 116 \\
\hline & AS & CTTGCTGGTCTCCAAGTAACG & & \\
\hline \multirow[t]{2}{*}{$A L P$} & $\mathrm{~S}$ & GGAGCACAGGAAGTTGGGAC & 55 & 393 \\
\hline & AS & GCGTGCTTGAGCTGAAGCTA & & \\
\hline \multirow[t]{2}{*}{ RUNX2 } & $\mathrm{S}$ & GTGACACCGTGTCAGCAAAG & 55 & 356 \\
\hline & AS & GGAGCACAGGAAGTTGGGAC & & \\
\hline \multirow[t]{2}{*}{ OCN } & S & CAAGTCCCACACAGCAGCTT & 55 & 370 \\
\hline & AS & AAAGCCGAGCTGCCAGAGTT & & \\
\hline \multirow[t]{2}{*}{ Col-I } & S & TCTCCACTCTTCTAGTTCCT & 55 & 269 \\
\hline & AS & TTGGGTCATTTCCACATGC & & \\
\hline \multirow[t]{2}{*}{ GAPDH } & S & TGGATTTGGACGCATTGGTC & 55 & 211 \\
\hline & AS & TTTGCACTGGTACGTGTTGAT & & \\
\hline \multirow[t]{2}{*}{ Shh } & S & AAAGCTGACCCCTTTAGCCTA & 60 & 119 \\
\hline & AS & TGAGTTCCTTAAATCGTTCGGAG & & \\
\hline \multirow[t]{2}{*}{ Smo } & S & GTGCTGTCTACATGCCCAAGT & 62 & 128 \\
\hline & AS & GCAACGCAGAAAGTCAGGC & & \\
\hline \multirow[t]{2}{*}{ Ptch1 } & $\mathrm{S}$ & GCCTTCGCTGTGGGATTAAAG & 61 & 118 \\
\hline & AS & СТTCTCСTATCTTCTGACGGGT & & \\
\hline \multirow[t]{2}{*}{ Gli1 } & S & CCAAGCCAACTTTATGTCAGGG & 61 & 130 \\
\hline & AS & AGCCCGCTTCTTTGTTAATTTGA & & \\
\hline \multirow[t]{2}{*}{ Gli2 } & S & CAACGССТАСТСТСССАGAC & 61 & 155 \\
\hline & AS & GAGCCTTGATGTACTGTACCAC & & \\
\hline \multirow[t]{2}{*}{ Gli3 } & S & CACAGCTCTACGGCGACTG & 62 & 168 \\
\hline & AS & CTGCATAGTGATTGCGTTTCTTC & & \\
\hline \multirow[t]{2}{*}{ Sufu } & $\mathrm{S}$ & CGGACCCCTTGGACTATGTTA & 60 & 182 \\
\hline & AS & CTTCAGACGAAACGTCAACTCA & & \\
\hline \multirow[t]{2}{*}{ Shh-promoter } & $\mathrm{S}$ & GGTACCGTGGCCACCTGTGATTATCC & 60 & 280 \\
\hline & AS & GAGCTCTGAGGACTTGTGAGCTGTCC & & \\
\hline
\end{tabular}

\section{Bone marrow mesenchymal stem cell (BM- MSC) cultures and cytochemical staining}

Tibiae and femurs of wild-type and $\mathrm{p} 27^{-/-}$mice were removed under aseptic conditions, and bone marrow cells were flushed out with DMEM containing $10 \%$ FCS, $50 \mu \mathrm{g} / \mathrm{mL}$ ascorbic acid, $10 \mathrm{mM}$ $\beta$-glycerophosphate, and $10^{-8} \mathrm{M}$ dexamethasone. Cells were dispersed by repeated pipetting, and a single-cell suspension was achieved by forcefully expelling the cells through a 22-gauge syringe needle. Total bone marrow cells were cultured in six-wellplates at $10^{6}$ cells/well in $2 \mathrm{~mL}$ of the abovementioned medium in the absence or presence of Shh-N (200 ng/ml) or Shh antagonist KAADCyclopamine (KAAD,2.5 $\mu \mathrm{M})$. Medium was changed every 3 days, and cultures were maintained for 10 to 14 days. At the end of the culture period, cells were washed with PBS, fixed with PLP fixative, and stained cytochemically for ALP as described previously [25] to determine ALP-positive CFU-f (CFU-fap). After petri dishes were dried and imaged, they were stained with methyl blue to determine total CFU-f. Cellular senescence staining was performed with a cellular senescence $\beta$-galactosidase staining kit (\# C0602,
Beyotime Biotechnology, Wuhan, China) according to the manufacturer's protocol.

\section{Overexpression of p27 in BM-MSCs}

BM-MSCs derived from WT mice were transfected with mouse p27-pCDNA3.1 (OV-p27) or vector plasmids which were purchased from Hanbio Co., Ltd. (Shanghai, China). BM-MSCs in the logarithmic phase were seeded into the 6-well plates $\left(2 \times 10^{5}\right.$ cells/well $)$ and cultured for $24 \mathrm{~h}$. Cell transfection was then performed using Lipofectamine $3000 \AA$ (Life Technologies, USA), cells were plated in 24-well plates and cultured with DMEM supplemented with $10 \%$ platelet lysate and 1\% penicillin/streptomycin, and maintained under normal tissue culture conditions $\left(37^{\circ} \mathrm{C}, 5 \% \mathrm{CO}_{2}\right.$ in a humidified atmosphere) for $24 \mathrm{~h}$ before transfection. Two different Lipofectamine $3000 \AA$ reagent and quantities of plasmid/DNA ratio were compared, and five cell confluences were tested. With the two best cell concentrations, four cell passages were compared. The protocol was performed according to the supplier's instructions. Briefly, plasmid DNA was mixed with OPTI-MEM (Life Technologies, USA) and the P3000 reagent (Life Biotechnologies, USA) in a microcentrifuge tube. In a separate tube, Lipofectamine $3000 \AA$ reagent was diluted in OPTIMEM. The contents of the two tubes were then combined by gentle pipetting and incubated at room temperature for $5 \mathrm{~min}$, allowing the formation of DNA/lipid complexes. Then, the transfection mixture was added to the cells in culture. All transfection experiments were performed in triplicate.

\section{Iconographic and histopathological analyses}

Femurs or tibias were removed and analyzed by radiography, micro-computed tomography, histology, histochemistry, and immunohistochemistry as we described previously [5, 26]. Histochemical staining for ALP [27] and tartrate resistant acid phosphatase (TRAP) [28] were performed on the decalcified paraffin-embedded sections as we previously described. Immunohistochemistry was performed with the primary antibodies against Shh (ab135240; Abcam, Cambridge, MA, USA), Bmi1 (10832-1-AP; Proteintech, USA), and Gli2 (18989-1-AP; Proteintech, USA), Col-I (34710; Abcam, Cambridge, MA, USA).

\section{Immunocytochemistry}

WT, Bmi1\%- and p27-/-BM-MSCs were seeded in $3.5 \mathrm{~cm}$ petri dishes and incubated at $37{ }^{\circ} \mathrm{C}$ with $5 \%$ humidification for $24 \mathrm{~h}$. WT BM-MSCs were transfected with mouse p27-pCDNA3.1 (OV-p27) or vector plasmids. Then the BM-MSCs were treated with Shh-N $(200 \mathrm{ng} / \mathrm{ml})$ or with Shh antagonist 
KAAD-Cyclopamine (KAAD, $2.5 \mu \mathrm{M})$ for 10 days. After 10 days, culture medium was discarded. Immunocytochemistry was then performed as described previously [29] with the primary antibodies against Ki67 (ab15580; Abcam, Cambridge, MA, USA).

\section{Double calcein labeling}

Double calcein labeling was performed by intraperitoneal injection of mice with $10 \mathrm{~g}$ calcein $/ \mathrm{g}$ body weight (C-0875Sigma-Aldrich, St. Louis, MO, USA) at 10 days and 3 days before death as described [30].

\section{Western blots}

Proteins were extracted from bone tissue, and immunoblotting was carried out as we described previously [31]. Immunoblotting was performed with the primary antibodies against Shh (ab135240; Abcam, Cambridge, MA, USA), Bmi1 (10832-1-AP; Proteintech, USA), Gli1 (ab49314; Abcam, Cambridge, MA, USA), Gli2 (18989-1-AP; Proteintech, USA), Gli3 (ab69838; Abcam, Cambridge, MA, USA), Ihh (ab39634; Abcam, Cambridge, MA, USA), Ptch1 (ab53715; Abcam, Cambridge, MA, USA), Sufu (\#C54G2; Cell Signaling Technology, Beverly, MA, USA) and Smo (ab236465,Abcam, Cambridge, MA, USA). The $\beta$-actin (BS6007M; Bioworld Technology, Bloomington, MN, USA) was used as the control for total protein.

\section{Chromatin immunoprecipitation}

MEFs were plated in 20-cm plates and the cells grown to about $70 \%$ confluence. Chromatin immunoprecipitation was performed with the Magna ChIPTM Chromatin Immunoprecipitation A kit (Millipore, Billerica, MA, USA, 2931149) according to the manufacturer's instruction. Chromatin samples were incubated with antibody against E2F4 (Millipore, MABE160, Billerica, MA, USA). The immunoprecipitated DNA samples were then analyzed by PCR and the samples were run on agarose $(2 \%)$ gel electrophoresis for visualization. The primers used for the analysis of E2F4 binding are as follows:

- forward primer, 5-GGTACCGTGGCCACCTGT GATTATCC-3;

- reverse primer, 5- GAGCTCTGAGGACTTGT GAGCTGTCC-3.

\section{Dual luciferase assay}

Mouse E2F4 gene was cloned into the vector pCDNA3.1 (Genechem Co., Ltd., Shanghai, China). For transfection experiments, the chimeric genes of the Shh promoter plasmid were constructed in a
GV148-basic vector (Genechem Co., Ltd., Shanghai, China) by ligating the 5 '-flanking regions of the mouse Shh gene upstream of the luciferase gene. Mouse MEF cells were plated into 24 -well cell culture plates 1 day before transfection. The transfections included $1 \mu \mathrm{g}$ each of pCDNA3.1-basic and GV148-basic; E2F4 over-expressing pCDNA3.1 and GV148-basic; E2F4 over-expressing pCDNA3.1 and GV148-mutant; E2F4 over-expressing pCDNA3.1 and GV148-Shh promoter; E2F4 over-expressing pCDNA3.1 and GV148-mutant, E2F4 over-expressing pCDNA3.1 and GV148-Shh promoter. These were respectively co-transfected with Firefly luciferase (Fluc) Renilla luciferase (Rluc) into mouse MEF cells using X-treme GENE HP DNA Transfection Reagent (Cat\#6366236001, Roche Diagnostics Corp., Switzerland) according to the manufacturer's protocol. Two days later, the promoter-driven luciferase activity was measured using the DualLuciferase ${ }^{\circledR}$ Reporter Assay system (Cat\# E1910, Promega Corporation, Madison, WI, USA).

\section{Statistical analysis}

All analyses were performed using GraphPad Prism software (Version 6.07; GraphPad Software Inc., San Diego, CA, USA) as previously described (36). All statistical results are expressed as mean \pm s.e.m. and are representative of at least three separate experiments ( $\mathrm{n}>6 /$ group). Differences between two groups were analyzed using 2-tailed unpaired Student's $t$-test. $\mathrm{P}$ values $<0.05$ were considered statistically significant.

\section{Results}

\section{Deletion of p27 stimulates osteoblast formation and osteogenesis}

We first compared long bone phenotypes of 4-week-old p27 deficient and wild-type mice. The results revealed that bone volume (Figs. 1A \& B), osteoblast numbers (Figs. $1 \mathrm{C} \&$ D), alkaline phosphatase (ALP) positive area (Figs.1E \& F) and type I collagen positive area (Figs. $1 \mathrm{G} \& \mathrm{H}$ ) were all significantly increased, and osteoclast number and surface (Figs. 1I-K) were also increased in p27 deficient mice compared with wild-type littermates in vivo. We next examined BM-MSC cultures ex vivo. We found that total CFU-f, ALP positive CFU-f and the percentage of Ki67 positive cells were significantly increased (Figs. 1L-Q) and expression levels of the osteogenic genes, including Runx2, ALP, type I collagen and osteocalcin $(O C N)$ were upregulated significantly (Figs. 1R) in BM-MSC cultures from p27 deficient mice compared with wild-type littermates. These results indicated that deletion of p27 could stimulate 
the proliferation of BM-MSCs and accelerate their osteoblastic differentiation, subsequently, increasing
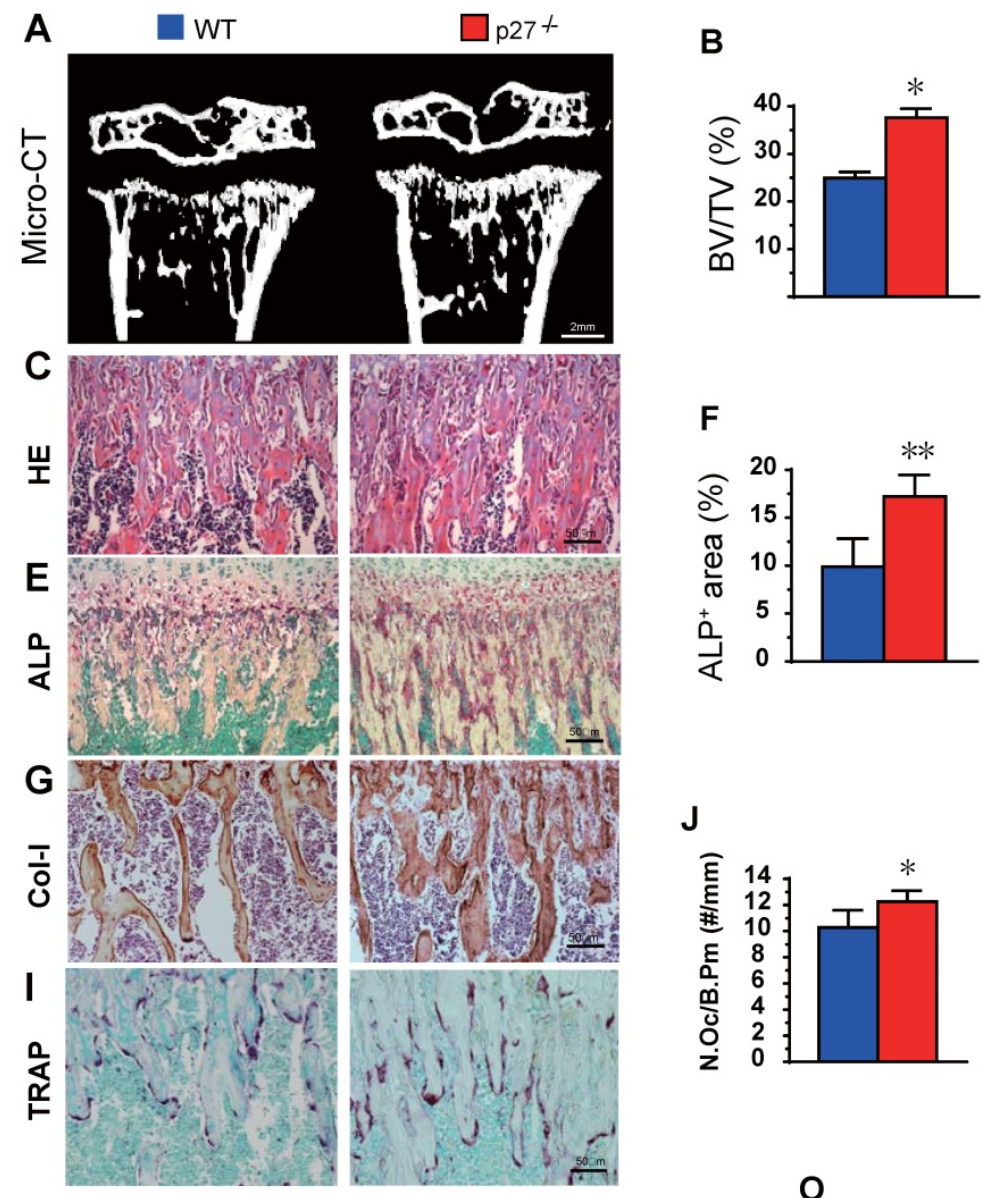

bone formation although deletion could also slightly increase osteoclasts.
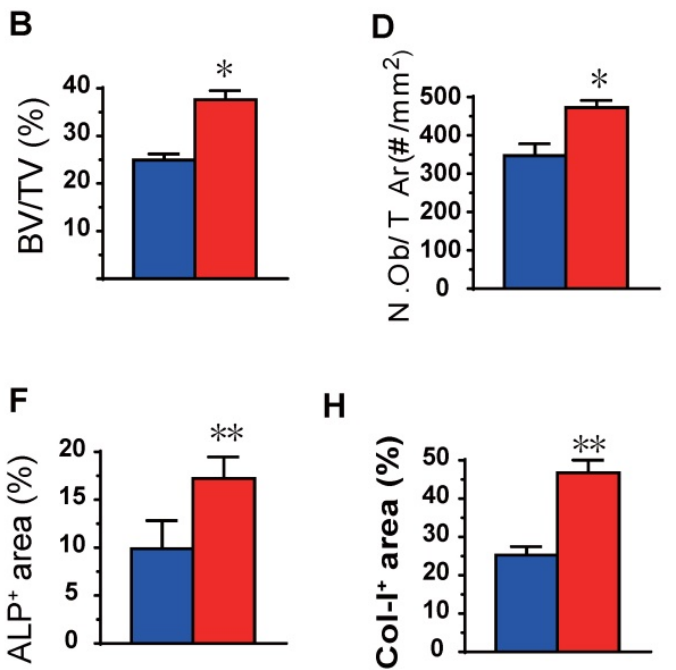

H
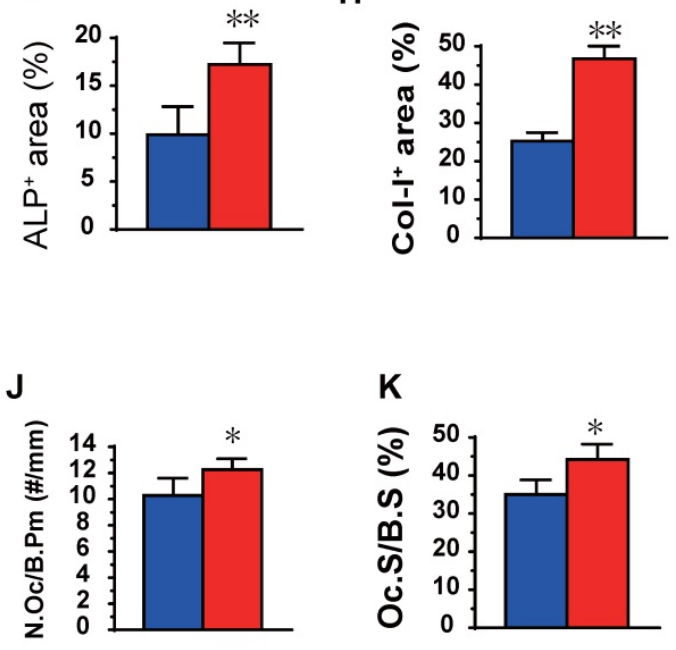
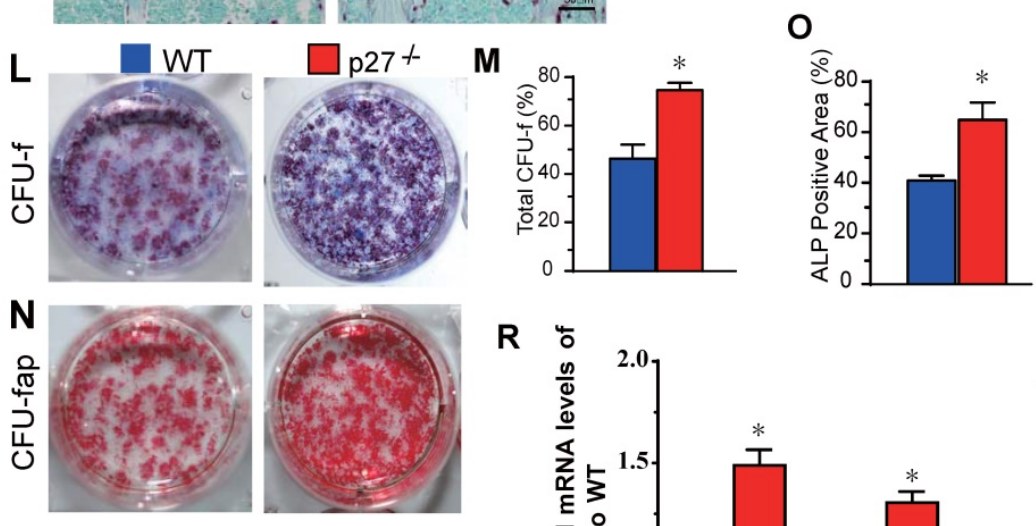

$\mathbf{R}$

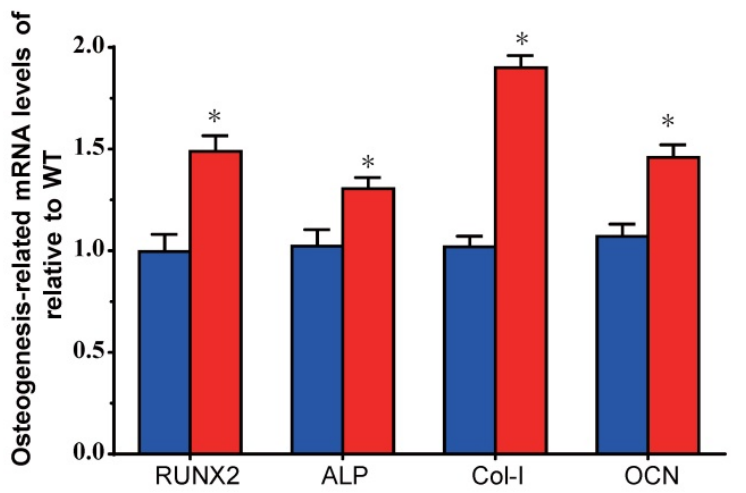

Figure 1. Effect of p27 deficiency on osteoblastic bone formation and osteogenesis. (A) Representative micro-CT scans of 3-dimensional longitudinal reconstructions of proximal ends of tibiae and midshaft diaphysis from 4-week-old WT and P27-/- mice, and (B) Trabecular bone volume relative to tissue volume (BV/TV, \%). Representative micrographs of paraffin-embedded sections of tibias from 4-week-old WT and p27-^- mice showing (C) H\&E staining and (D) the number of osteoblasts per mm ${ }^{2}$ tissue area (N.Ob/T.Ar, \#/mm²), (E) histochemical staining for ALP and (F) ALP-positive areas as a percent of the tissue area (\%), (G) immunostaining for type I collagen (Col-I), and $(\mathbf{H})$ the percentages of Col-I positive areas, (I) histochemical staining for TRAP, (J) the number of osteoclasts/bone perimeter $(\mathrm{Oc} . \mathrm{N} / \mathrm{B} . \mathrm{Pm}, \# / \mathrm{mm})$ and $(\mathbf{K})$ osteoclast surface/bone surface (Oc.S/BS, \%). BM-MSCs from 4-week-old WT and p27---mice were cultured ex vivo in osteogenic differentiation medium for 10 days. Resulting cultures were analyzed as follows: (L) staining with methyl blue for the total CFU-f and (M) total CFU-f-positive areas, (N) cytochemical staining for ALP to show CFU-fap and (O) ALP-positive areas, $(\mathbf{P})$ immunocytochemical staining for Ki67 and $(\mathbf{Q})$ the percentage of Ki67 positive cells. Real-time RT-PCR analyses of BM-MSC extracts for the expression of (R) Runx2, ALP, Col-l and OCN. Messenger RNA expression assessed by RT-PCR is expressed as a ratio relative to GAPDH expression. Values are mean $\pm s$. e. $m$. of 5 determinations per group. *: $P<0.05 ; * *: P<0.01$, compared with WT mice. 
A

Hedgehog signaling pathway
Basal cell carcinoma
Pathways in cancer
Proteoglycans in cancer
Axon guidance
Prion diseases
Primary immunodeficiency
ErbB signaling pathway
Vasopressin-regulated water reabsorption
cAMP signaling pathway

C

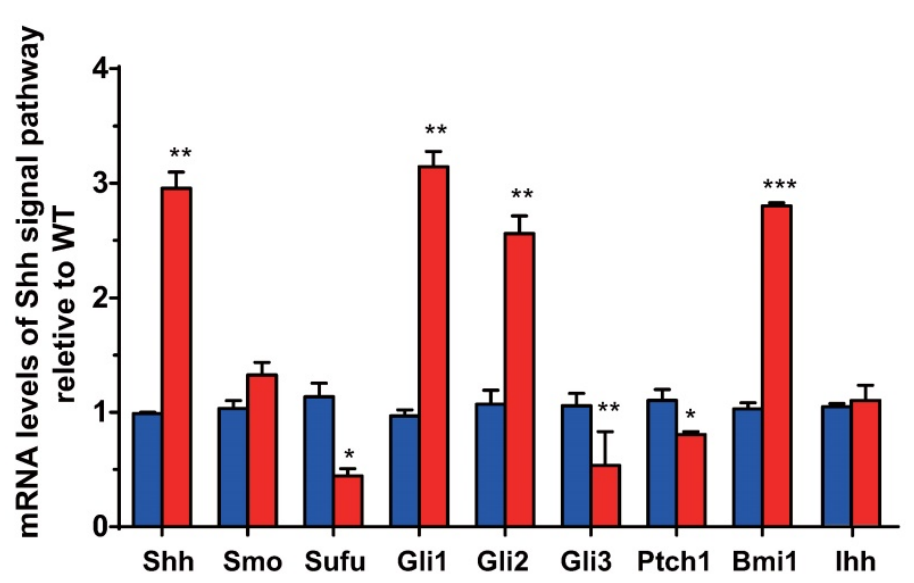

E

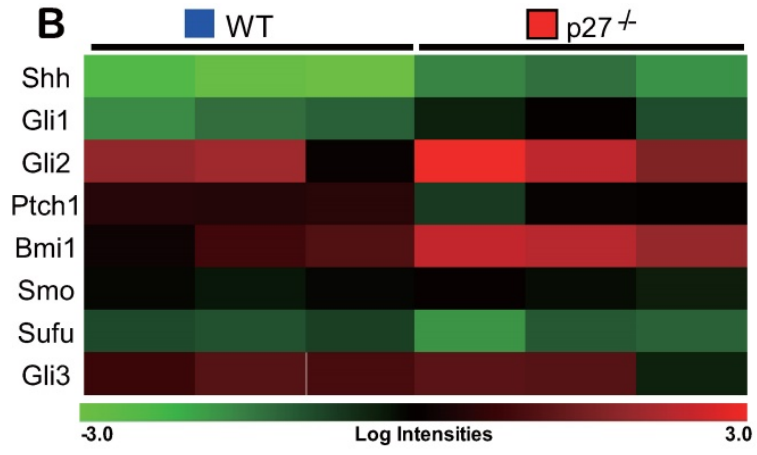

D $\quad$ WT $\square \mathrm{p} 27+\mathrm{MW}(\mathrm{Kd})$

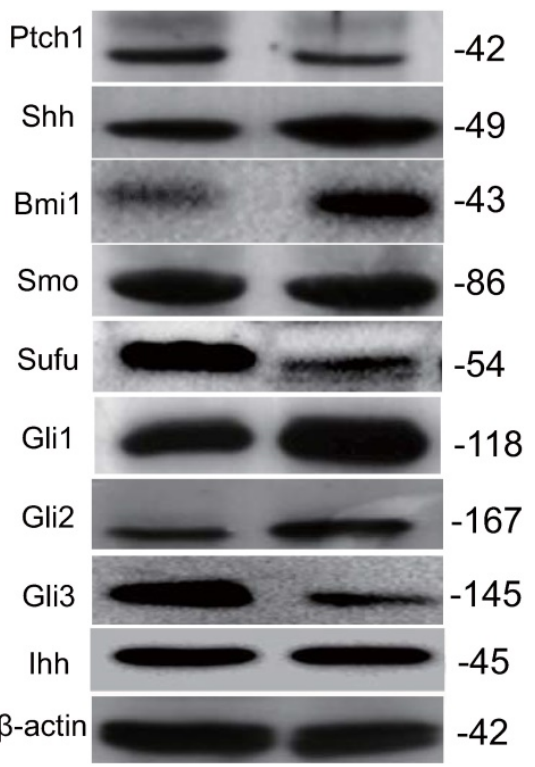

Figure 2. Sonic hedgehog signaling pathway is activated in the bone tissue of p27 deficient mice. (A) Kyoto Encyclopedia of Genes and Genomes (KEGG) pathways of differentially expressed mRNAs and (B) the heat map of Shh signaling genes differentially expressed in bone tissue of 3 WT and 3 p27-l-mice. Confirmation of results of microarray using (C) real-time RT-PCR and (D) Western blots. (E) Relative protein expression levels of Shh signaling molecules. Values are mean \pm s. e. m. of 3 determinations per group. *: $P<0.05, * *: P<0.01$, ***: $P<0.001$ compared with WT mice.

\section{The Sonic hedgehog signaling pathway is activated in the bone tissue of p27 deficient mice}

To identify the critical molecules which mediated osteogenesis enhanced by p27 deficiency, a microarray analysis was performed in wild-type and p27 deficient bone tissue using 44,170 mouse probes. The differential expression of 445 genes (DEGs) (>1.5-fold up- or downregulated genes, $\mathrm{p}<0.05$ ) was detected in the bone tissue of 4 -week-old p27-/- mice compared with their wild-type littermates (Supplemental Table 1). The Kyoto gene and genome pathway encyclopedia (KEGG) enrichment analysis was performed by using the Enrichr database [32], and results showed that 445 DEGs were significantly enriched in the hedgehog signaling pathway (Fig. 2A). The expression levels (log scale) of the molecules related to Shh signaling pathway were reordered and displayed in a heat map, with the spectrum ranging from green (low level) to red (high level), as presented in Fig. 2B. By real-time RT-PCR and Western blots we 
confirmed the alterations of Shh signaling related molecules detected by the microarray. At both mRNA and protein levels, the expression of Shh, Gli1 and 2 and their target gene Bmi1 was significantly up-regulated. The expression of smoothened (Smo) was up-regulated but insignificantly, and the expression of suppressor of fused (Sufu), Patched 1 (Ptch1) and Gli3 was significantly down-regulated in p27 deficient mice compared with wild-type littermates (Figs. 2C-E). We also examined the mRNA and protein expression levels of Indian hedgehog (Ihh) and found that they were not altered in p27 deficient mice compared with wild-type littermates (Figs. 2C-E). These results implied that p27 deficiency can activate the Shh signaling pathway in bone tissue.

\section{Shh signaling mediates p27 deficiency-induced osteogenesis in vitro}

To explore whether Shh signaling mediated p27 deficiency-induced osteogenesis, BM-MSCs derived from wild-type or p27 deficient mice were cultured in the absence or presence of $2.5 \mu \mathrm{M}$ Shh antagonist KAAD-Cyclopamine (KAAD) for 10 days. The cells were stained with methyl blue or cytochemically for alkaline-phosphatase (ALP) to detect alterations of total CFU-f or ALP-positive CFU-f (CFU-fap), respectively, and immunocytochemical staining for Ki67. Results showed that the percentages of both total CFU-f, CFU-fap areas and the percentage of Ki67 positive cells were significantly increased in p27 deficient BM-MSC cultures relative to wild-type BM-MSC cultures but were dramatically decreased in the p27 deficient BM-MSC cultures treated with KAAD (Figs. 3A-E). We then overexpressed p27 in BM-MSCs derived from wild-type mice and cultured them in the absence or presence of $200 \mathrm{ng} / \mathrm{ml}$ recombinant Sonic hedgehog N-Terminus Protein (Shh-N) for 10 days. We found that the percentages of both total CFU-f and CFU-fap areas and the percentage of Ki67 positive cells were significantly decreased in p27 overexpressed BM-MSC cultures compared to wild-type BM-MSC cultures and moderately increased in p27 overexpressed BM-MSC cultures treated with Shh-N (Figs. 3F-J). We also found that $\mathrm{p} 27$ overexpression significantly increased the percentage of senescence-associated $\beta$-galactosidase (SA- $\beta$-gal) positive BM-MSCs (Figs. $3 \mathrm{~K} \& \mathrm{~L}$ ). These results indicate that Shh signaling mediated p27 deficiency-induced osteogenesis.

\section{Shh signaling mediates p27 deficiency-induced osteoblastic bone formation in vivo}

To determine whether Shh signaling mediated p27 deficiency-induced osteoblastic bone formation in vivo, 8-week-old wild-type and p27/- mice were given the Shh antagonist vismodegib in their diet for 2 weeks, and their long bone phenotypes were then analyzed. The results showed that the trabecular and cortical bone volume (Figs. 4A-D), osteoblast number (Figs. 4E-F), type I collagen positive area (Figs.4G-H), bone formation rate and mineral apposition rate (Figs.4I-K), osteoclast surface (Figs.4L \& M) and mRNA expression levels of Runx2, ALP, type I collagen and osteocalcin (Figs. 4N-Q) were all increased significantly in p27 deficient mice compared with their wild-type littermates on the normal diet, but these parameters were significantly decreased in vismodegib-treated wild-type and p27 deficient mice compared with mice of the same genotype on the normal diet. However, no significant differences in these parameters were detected between vismodegib-treated wild-type and p27 deficient mice. These results demonstrated that inhibition of Shh signaling can block p27 deficiency-induced osteoblastic bone formation in vivo and support the concept that p27 is a negative regulator of the Shh signaling pathway in bone tissue.

\section{Deletion of p27 releases Shh transcription suppression mediated via E2F4}

Previous studies suggested that $\mathrm{p} 27$ has a role as a transcriptional repressor in combination with p130 and E2F4. Immunoprecipitation experiments revealed that p27 co-immunoprecipitated with endogenous E2F4 and p130 [2], however, it is unclear whether E2F4 mediates Shh transcription. To answer this question, we identified a putative E2F4 binding site in the promoter region of the Shh gene (retrieved from the NCBI mouse genome database) by computerassisted analysis (Fig. 5A). Using a ChIP approach, we confirmed that E2F4 had the ability to physically bind the Shh promoter in wild-type mouse embryonic fibroblasts (MEFs) and this binding was more enriched in p27 deficient MEFs (Figs. 5B \& C). Luciferase assays showed that luciferase activities were increased significantly in wild-type MEFs transfected with PGL3-E2F4 plasmid compared with the empty plasmid and were increased more dramatically in p27 deficient MEFs transfected with PGL3-E2F4 plasmid. In contrast, luciferase activities were not increased in wild-type or p27 deficient MEFs transfected with PGL3-E2F4 mutant plasmid compared with the empty plasmid (Figs. 5D \& E). These results indicate that $\mathrm{p} 27$ acts as a transcriptional repressor in combination with E2F4 to suppress Shh transcription. 
A

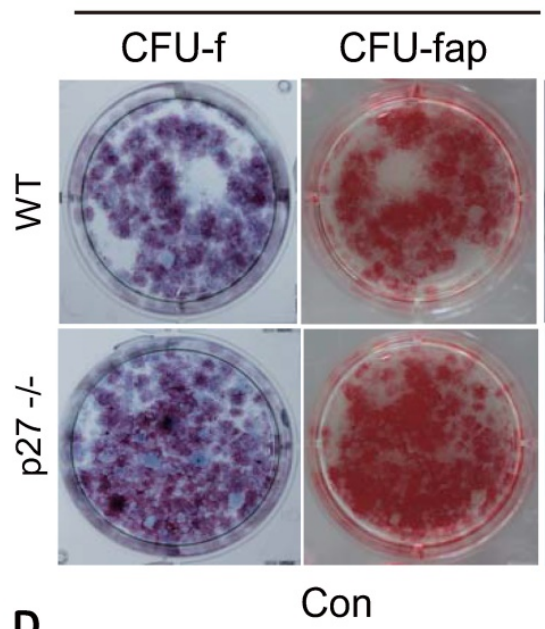

D

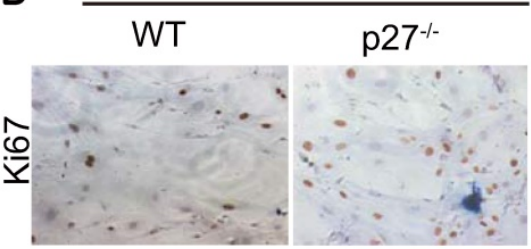

$\mathbf{F}$

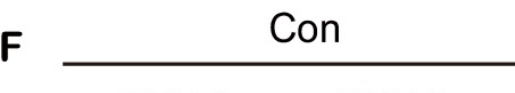

5

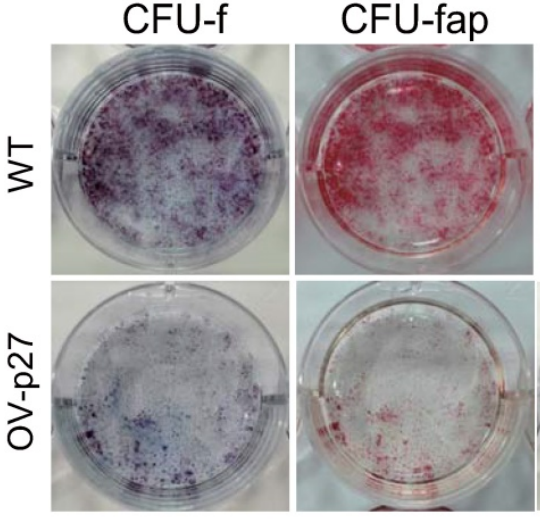

1

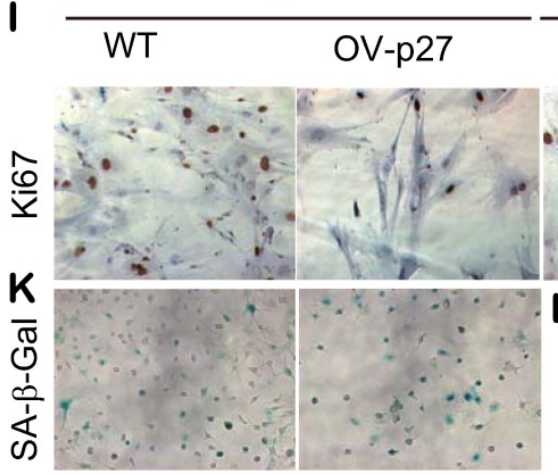

+ KAAD
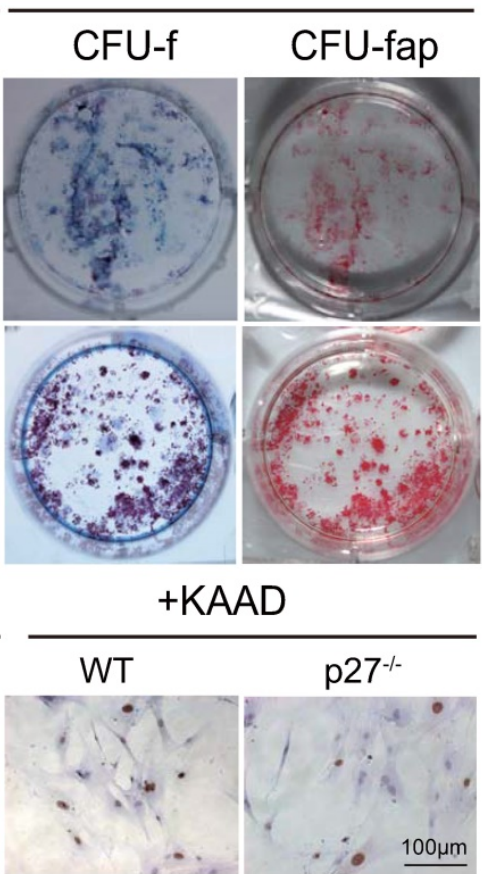

+ Shh-N

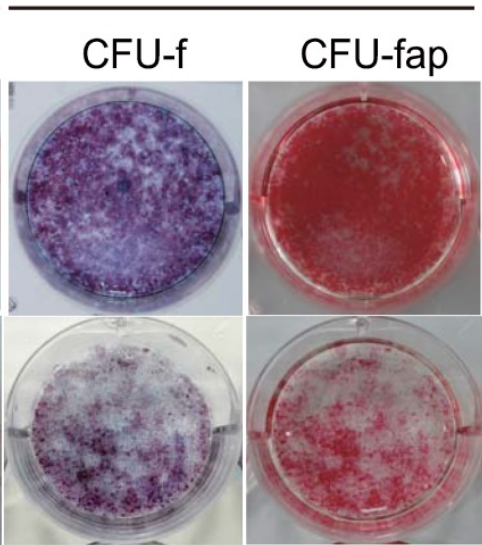

+Shh-N

WT

WT
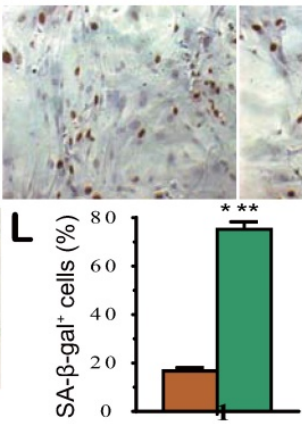

B $\square \mathrm{WT} \square \mathrm{p} 27^{-/-}$
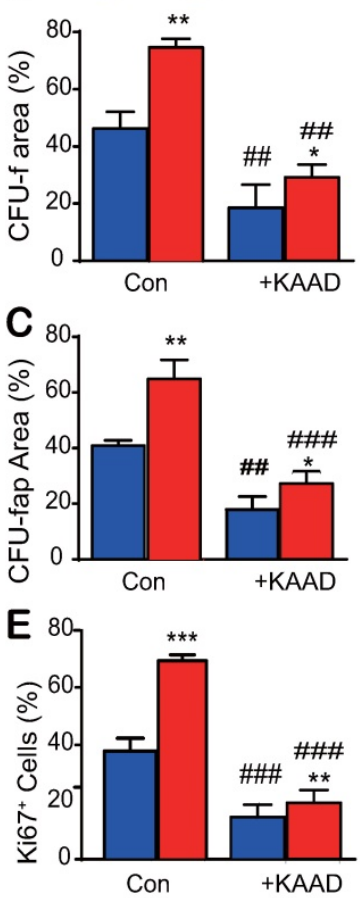

G $\quad$ WWT 0 OV-p27
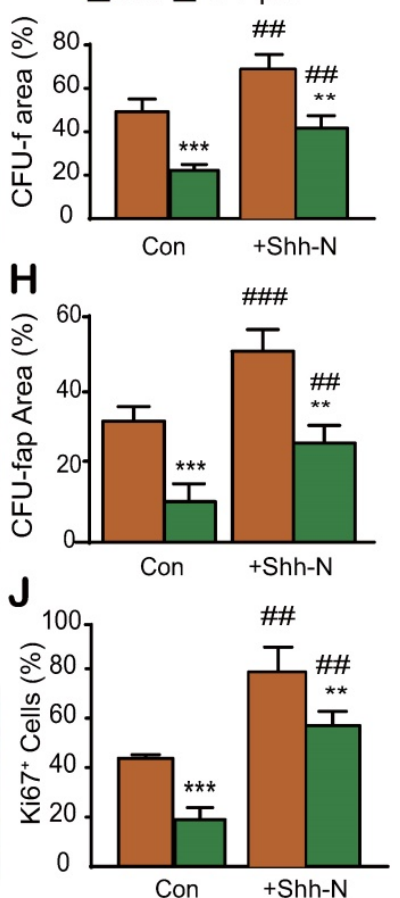

Figure 3. Shh signaling mediates p27 deficiency-induced osteogenesis in vitro. BM-MSCs derived from WT mice and p27- mice were cultured in the absence or presence of $2.5 \mu \mathrm{M}$ Shh antagonist KAAD-Cyclopamine (KAAD) for 10 days. Resulting cells were stained (A) with methyl blue or cytochemically for alkaline-phosphatase (ALP) to detect alterations of total CFU-f or ALP-positive CFU-f (CFU-fap), respectively. (B) CFU-f positive areas and (C) CFU-fap positive areas relative to culture dish areas. (D) Representative micrographs of immunocytochemical staining for Ki67 and (E) the percentage of Ki67 positive cells. BM-MSCs derived from wild-type mice were overexpressed with p27 and were cultured in the absence or presence of $200 \mathrm{ng} / \mathrm{ml}$ Shh-N for 10 days. Resulting cells were stained (F) for total CFU-f and CFU-fap. (G) CFU-f positive areas and (H) CFU-fap positive areas relative to culture dish areas. (I) Representative micrographs of immunocytochemical staining for Ki67 and (J) the percentage of Ki67 positive cells. (K) Representative micrographs of cytochemical staining for SA- $\beta$-gal and (L) the percentage of SA- $\beta$-gal positive cells. Values are mean \pm s. e. $m$. of 3 determinations per group. *: $P<0.05, * *: P<0.01$, ***: $P<0.001$ compared with WT BM-MSCs. \#\#: $P<0.01$, \#\#: $P<0.001$ compared with genotype matched BM-MSCs treated with KAAD or Shh-N. 

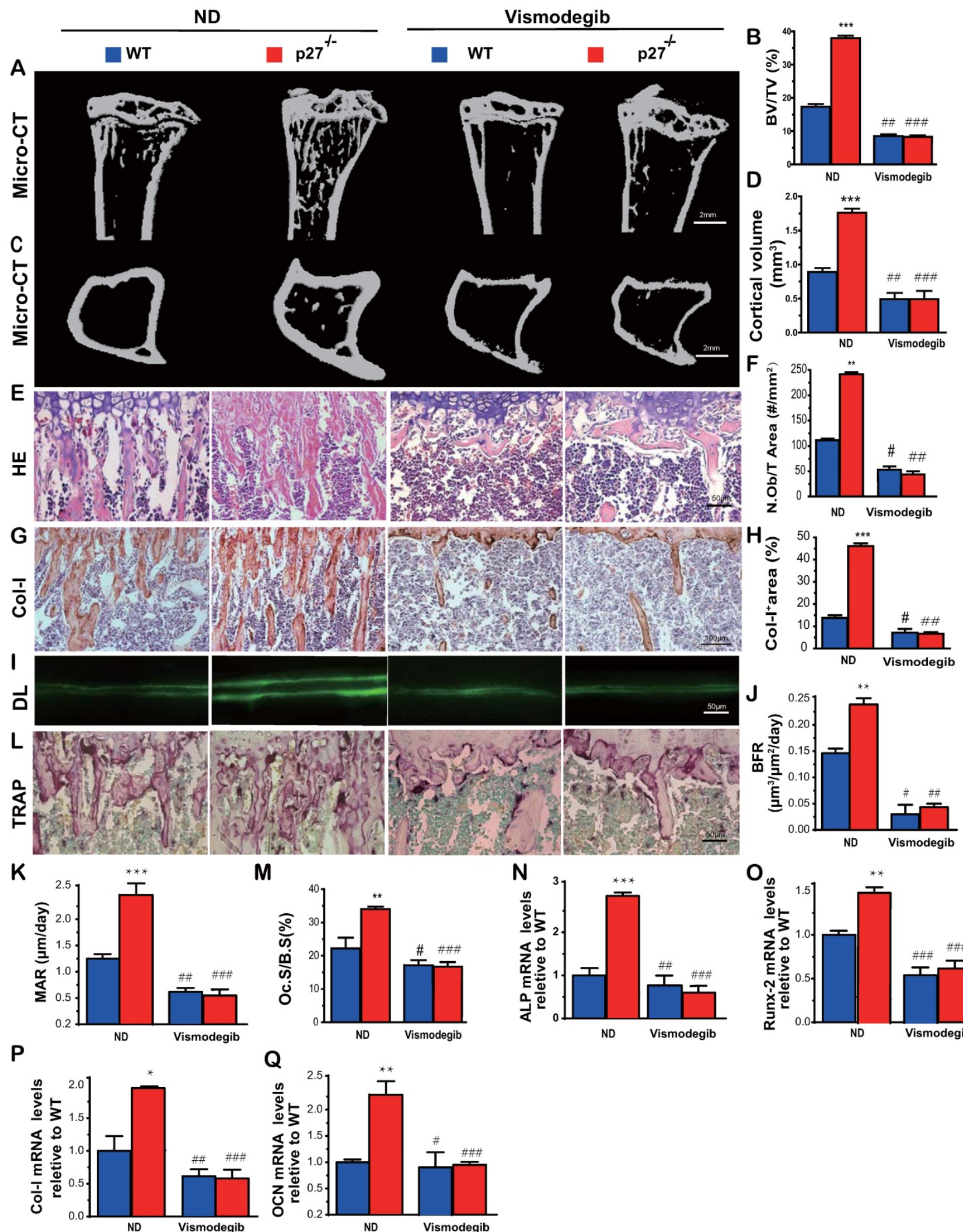

Figure 4. Shh signaling mediates p27 deficiency-induced osteoblastic bone formation in vivo. (A, C) Representative micro-CT scans of 3-dimensional longitudinal reconstructions of proximal ends of tibiae and midshaft diaphysis from 8-week-old WT and p27-l- mice fed a normal diet (ND) or a diet with Shh antagonist Vismodegib for 2 weeks after weaning. (B) Trabecular bone volume relative to tissue volume (BV/TV, \%). (D) Cortical bone volume $\left(\mathrm{mm}^{3}\right)$. Representative micrographs of paraffin-embedded sections of tibias from 8-week-old WT and $\mathrm{p} 27-$ - mice: $(\mathbf{E})$ stained with $\mathrm{H} \& \mathrm{E}$ and $(\mathbf{F})$ the number of osteoblasts per $\mathrm{mm}^{2}$ tissue area $(\mathrm{N} . \mathrm{Ob} / \mathrm{T} . \mathrm{Ar}$, \#/mm²), (G) stained immunohistochemically for type I collagen (Col-I) and (H) Col-I-positive areas as a percent of the tissue area (\%), (I) Double calcein labeling (DL), (J) bone formation rate (BFR, $\mu \mathrm{m}^{3} / \mu \mathrm{m}^{2} / \mathrm{day}$ ) and (K) mineral apposition rate (MAR, $\mu \mathrm{m} / \mathrm{day}$ ), (L) histochemical staining for TRAP and (M) osteoclast surface/bone surface (Oc.S/BS, \%). Real-time RT-PCR analyses of long bone extracts for the expression of $(\mathbf{N}) A L P,(\mathbf{O})$ Runx2, (P) Col-I and $(\mathbf{Q}) O C N$. Messenger RNA expression assessed by RT-PCR was calculated as a ratio relative to the GAPDH mRNA level and expressed relative to WT control. Values are mean \pm s. e. $\mathrm{m}$. of 5 determinations per group. *: $P<0.05$; **: $P<0.01$ compared with WT mice. \#: $P<0.05$; 1 : $P<0.01$, \#\#: $P<0.001$ compared with genotype matched mice fed a normal diet. 

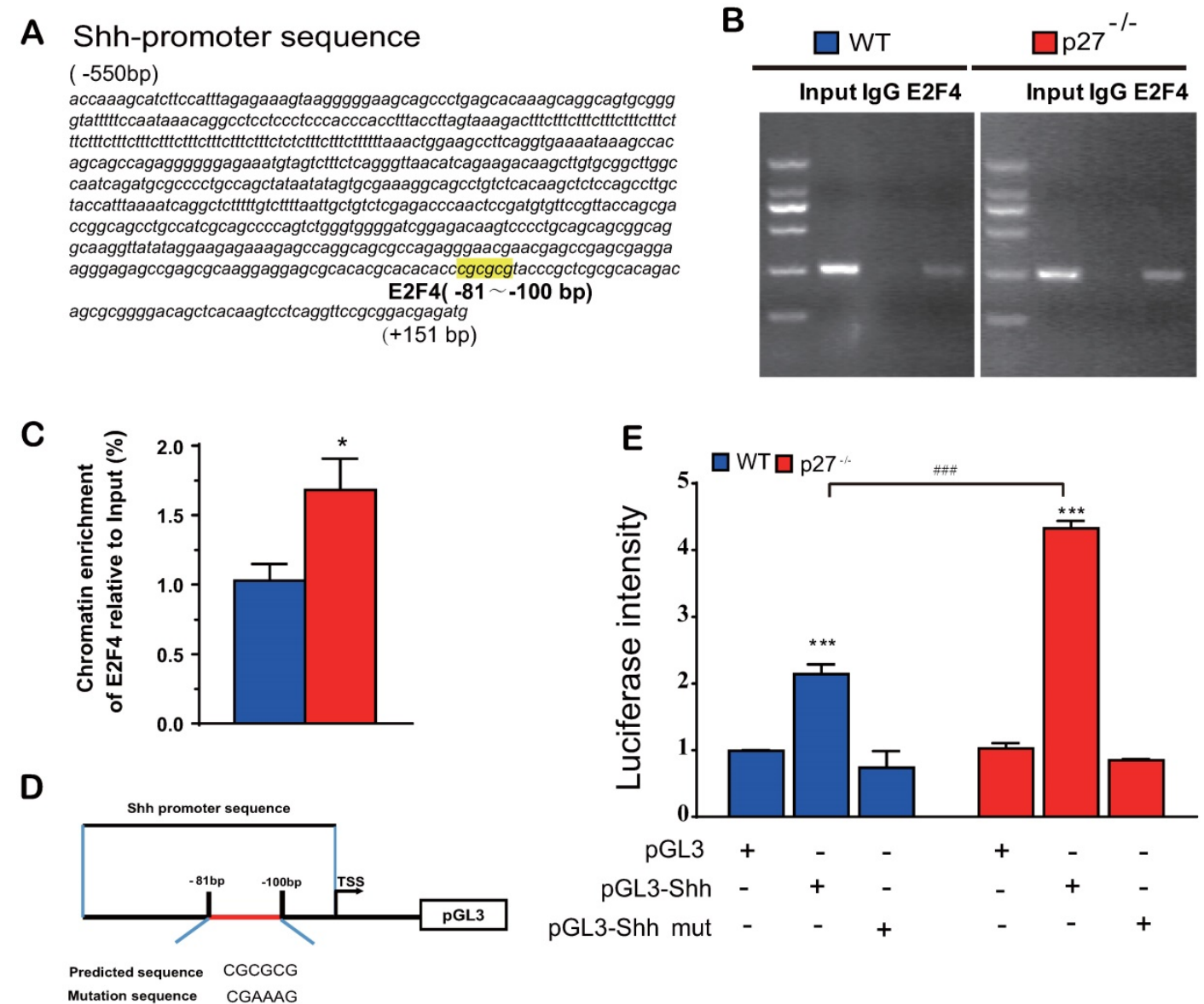

Figure 5. Deletion of p27 releases Shh transcription suppression mediated via E2F4. (A) A putative E2F4 binding site in the promoter region of the Shh gene highlighted in yellow color. (B \& C) Analysis of E2F4 binding to Shh promoter using ChIP assays in wild-type and p27 deficient MEFs. *: P<0.05 compared with wild-type MEFs. (D) Schematic structural diagram of PGL3-E2F4 promoter and mutant PGL3-E2F4 Luc reporter plasmid. (E) Luciferase activity driven by the Shh promoter in wild-type and P27 deficient MEFs. Values are mean \pm s. e. $m$. of 3 determinations per group. *: $P<0.05$; $* *: P<0.01$ compared with the empty plasmid. \#: $P<0.05$; \#: $P<0.01$, \#\#: $P<0.001$ compared with MEFs transfected with the same plasmid.

\section{Deletion of Bmil blocks p27 deficiency- induced osteoblastic bone formation in vivo}

To evaluate whether Bmi1 mediated p27 deficiency-induced osteoblastic bone formation in vivo, we generated p27-/-Bmi1 $/$ - double knockout mice and compared them with p27\%, Bmi1 $\%$, and wild-type littermates at 4 weeks of age. We found that the trabecular and cortical bone volume (Figs. 6A-D), osteoblast number (Figs. 6E \& F), type I collagen positive area (Figs. 6G \& H), osteoclast surface (Figs. $6 \mathrm{I} \& \mathrm{~J})$ and mRNA expression levels of Runx2, ALP, type I collagen and osteocalcin (Figs.6K-N) were all increased significantly in p27 deficient mice, and were all, except for osteoclast surface decreased dramatically in $\mathrm{Bmi1} /$ or $\mathrm{p} 27-/-\mathrm{Bmi1} /-$ mice compared with their wild-type littermates; in addition. these parameters except for osteoclast surface were significantly decreased in $\mathrm{p} 27^{-/-\mathrm{Bmi1}} / /-$ mice compared with p27/- mice (Fig. 6). The bone phenotype of $\mathrm{p} 27-\% \mathrm{Bmi1} \%$ mice closely resembled that of Bmi1/-mice (Fig. 6). These results suggest that Bmi1 deletion can block the activation of the Shh signaling pathway induced by p27 deficiency, and therefore can block p27 deficiency-induced osteoblastic bone formation in vivo.

\section{Discussion}

Cyclin dependent kinase inhibitor p27 regulates cell proliferation, cell motility and apoptosis. The p27 expression levels in several tumor types have both prognostic and therapeutic implications [33]. There are studies that have implied that p27 is also a critical factor in osteogenesis and osteoblastic bone formation [3-5], however, the mechanisms underlying its functions in bone metabolism is unclear. In this study, we first confirmed that deletion of p27 could enhance osteoblast formation and osteogenesis by comparing bone phenotypes of 4-week-old p27 deficient and wild-type littermates. To identify the critical molecules which mediated osteogenesis enhanced by p27 deficiency, we performed a microarray analysis in wild-type and p27 deficient bone tissue and the mRNA and protein levels of the molecules of interest were confirmed to be elevated or reduced by RT-PCR and Western blots. Our results demonstrated that 
deletion of p27 significantly upregulated the expression of Shh, Gli1 and 2 and their target gene Bmi1 and significantly downregulated the expression of Sufu, Ptch1 and Gli3 in bone tissue, but did not alter the expression level of Ihh. The critical function of hedgehog signaling in bone formation has been identified in the past two decades [34]. Shh acts at early stages of development to regulate patterning and growth [14], and also enhances the proliferation and osteoblastic differentiation of BM-MSCs [16] and of periosteal-derived mesenchymal progenitor cells [17]. Gli1-haploinsufficient mice exhibit reduced bone mass with impaired osteoblast differentiation [35]. In addition, deletion of Gli2 impaired endochondral bone development and displayed osteopenia [36].
Patch1 haploinsufficiency increases adult bone mass, and Ptch1-deficient osteoblast precursor cells differentiate into osteoblasts at an accelerated rate as a result of an enhanced response to Runx 2 and by reducing the generation of the Gli3 repressor [37]. Ligand-independent activation of hedgehog signaling in Sufu-deficient mice was similar to that observed in mice deficient in Ptch1 [38]. The deletion of Gli3 results in an increased ossification of calvarial bone, causing craniosynostosis [39]. Taken together with the previous data demonstrating the important role of hedgehog signaling in bone formation, the results of the present study, suggest that deletion of p27 enhances osteoblast formation and osteogenesis by activating the Shh signaling pathway in bone tissue.
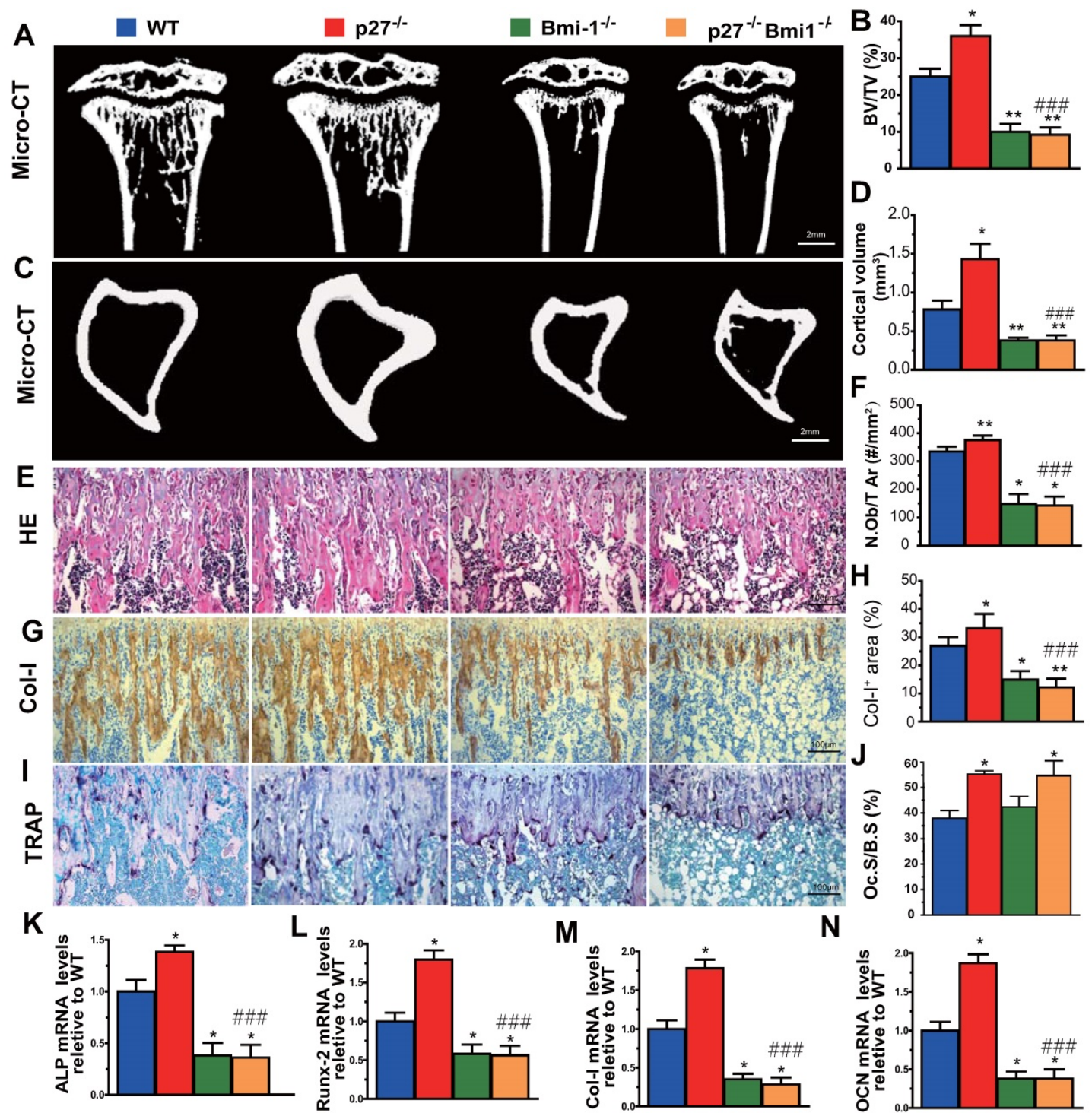

Figure 6. Deletion of Bmil blocks p27 deficiency-induced osteoblastic bone formation in vivo. (A, C) Representative micro-CT scans of 3-dimensional longitudinal reconstructions of proximal ends of tibiae and midshaft diaphysis from 4-week-old WT, p27 $/$, Bmil 1 - and p27-/-Bmi 1 $/$ - mice. (B) Trabecular bone volume relative to tissue volume

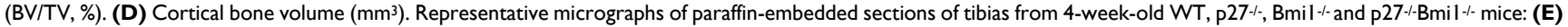
staining with H\&E and (F) the number of osteoblasts per $\mathrm{mm}^{2}$ tissue area (N.Ob/T.Ar, \#/mm²), (G) immunohistochemical staining for type I collagen (Col-I) and (H) Col-I-positive areas as a percent of the tissue area (\%), (I) histochemical staining for TRAP and (J) osteoclast surface/bone surface (Oc.S/BS, \%). Real-time RT-PCR analyses of long bone extracts for the expression of (K) ALP, (L) Runx2, (M) Col-l and (N) OCN. Messenger RNA expression assessed by RT-PCR was calculated as a ratio relative to the GAPDH mRNA level and expressed relative to WT control. Values are mean \pm s. e. $\mathrm{m}$. of 5 determinations per group. *: $P<0.05 ; * *$ : $P<0.01$ compared with WT mice. \#\#: $P<0.001$ compared with $\mathrm{P} 27_{-/-}^{-}$mice. 
To further demonstrate that Shh signaling mediated p27 deficiency-induced osteoblast formation in vitro, BM-MSCs derived from wild-type or p27 deficient mice were treated with the Shh antagonist KAAD-cyclopamine, and in response to this antagonist, osteogenic capacity was reduced significantly in both wild-type and p27 deficient BM-MSCs, but especially in p27 deficient BM-MSCs. We also found that overexpression of p27 in BM-MSCs significantly reduced osteogenesis by BM-MSCs; by contrast, the Shh agonist Shh-N significantly enhanced osteogenesis of BM-MSCs, and this enhancement was reduced significantly by overexpression of p27. Vismodegib is a hedgehog pathway inhibitor indicated for the treatment of adults with metastatic basal cell carcinoma [40]. When vismodegib was given in the diet to 8-week wild-type and p27 deficient mice for 2 weeks, the increased bone volume and osteoblastic bone formation parameters induced by p27 deficiency were completely blocked, in vivo. A previous study has demonstrated that inhibition of the hedgehog signaling pathway by cyclopamine treatment suppressed the expression of osteoblast-related genes and decreased bone mineralization, and that blocking hedgehog signaling through knockdown of Shh and Gli2 genes led to defective osteoblast differentiation; in contrast, promoting hedgehog signaling by knockdown of Ptch1 was beneficial to osteoblast differentiation [41]. Results from our study provide evidence that deletion of p27 enhances osteoblast formation and osteogenesis by activating Shh signaling in bone tissue.

Previous studies suggest that $\mathrm{p} 27$ has a role as a transcriptional repressor in coordination with p130 and E2F4 [2]. Immunoprecipitation experiments revealed that p27 co-immunoprecipitated with endogenous E2F4, p130, mSIN3A and histone deacetylases, indicating that they form complexes in vivo [2]. We detected a putative E2F4 binding site in the promoter region of the Shh gene, and using a ChIP approach, confirmed that E2F4 has the ability to physically bind the Shh promoter in wild-type MEFs and their binding was more enriched in p27 deficient MEFs. Luciferase assays demonstrated that the putative promoter region containing the predicted E2F4 binding sites of the Shh gene is sufficient to promote transcription of Shh, and Shh transcription was further enhanced by deletion of p27. Our results therefore indicate that $\mathrm{p} 27$ acts as a transcriptional repressor in coordination with p130 and E2F4 by suppressing Shh transcription via E2F4.

In previous studies we demonstrated that Bmi1 deficiency results in premature osteoporosis with reduced osteoblast formation and osteogenesis [10], whereas overexpression of Bmi1 in MSCs elicited antiosteoporosis effects by enhancing osteoblast formation and osteogenesis [11]. Recently we found that $1,25(\mathrm{OH})_{2} \mathrm{D}_{3}$ upregulated Bmi1 expression at a transcriptional level via the vitamin $\mathrm{D}$ receptor; $\mathrm{Bmi1}$ overexpression in MSCs corrected bone loss induced by $1,25(\mathrm{OH})_{2} \mathrm{D}$ deficiency and the bone anabolic action of exogenous $1,25(\mathrm{OH})_{2} \mathrm{D}_{3}$ administration was blocked by deletion of Bmi1; these studies implicated Bmi1 as a key downstream target of $1,25(\mathrm{OH})_{2} \mathrm{D}$, which plays a crucial role in preventing bone loss induced by $1,25(\mathrm{OH})_{2} \mathrm{D}$ deficiency [11]. Several lines of evidence have demonstrated that Bmi1 regulates self-renewal of stem cells through suppressing $\mathrm{p} 16 / \mathrm{Rb}$ and $\mathrm{p} 19 / \mathrm{p} 53 / \mathrm{p} 21$ signaling pathways and DNA damage, decreasing oxidative stress and maintaining mitochondrial function [42-44]. Furthermore, previous studies have also demonstrated that Bmil functioned as a downstream target of the hedgehog pathway [12, 13, 45]. Treatment with Shh or overexpression of Gli1 or Gli2 resulted in a 6-fold increase in expression of Bmi1 in human mammary stem/progenitor cells and these effects were blocked by the hedgehog pathway specific inhibitor cyclopamine [46]. Therefore, we considered whether Bmi1, as a critical downstream target of Shh, plays a key role in p27 deficiency induced osteoblast formation. Our results demonstrated that deletion of p27 also significantly upregulated Bmil expression at both mRNA and protein levels in bone tissue, whereas deletion of Bmi1 blocked p27 deficiency-induced osteoblastic bone formation in vivo. Results from this study indicate that p27 deficiency induced increased bone by activating Shh-Gli-Bmi1 signaling.

Although we demonstrated that a Sonic Hedgehog-Gli-Bmi1 signaling pathway is present in bone tissue and BM-MSCs, because we employed global knockouts of p27 and Bmi1 we cannot exclude the possibility that in vivo effects on bone metabolism partially result from their indirect actions. Bone-specific knockouts of p27 or Bmi1 could therefore be useful to identify direct versus indirect actions of p27 and Bmi1 in bone metabolism.

Overall, therefore, our results demonstrated that p27 deficiency induced bone anabolic action by activating Shh signaling and their target gene Bmi1, subsequently stimulating osteogenesis of BM-MSCs and osteoblastic bone formation; in contrast, deletion of Bmi1 blocked bone anabolic action induced by p27 deficiency and activation of Shh signaling. The results of this study indicate that the signaling pathway Shh-Gli-Bmi1 plays a critical role in p27 deficiency induced bone anabolic action, and suggest that Bmi1 may be an important therapeutic target for 
osteoporosis induced by activation of p27 signaling or inactivation of sonic hedgehog signaling.

\section{Abbreviations}

BM-MSCs: Bone marrow mesenchymal stem cells; p27: Cyclin-dependent kinase inhibitor 1B or p27Kip1; Bmi1: B-lymphoma Mo-MLV insertion region 1; p27-/: p27 Knockout; Bmi1-/-: Bmi1 Knockout; ALP: Alkaline phosphatase; Col-I: Type I collagen; OCN: Osteocalcin; DEGs: Differential expressed genes; Shh: Sonic Hedgehog; Smo: smoothened; Sufu: suppressor of fused; Ptch1: Patched 1; Indian hedgehog: Ihh; Sonic hedgehog N-Terminus Protein: Shh-N; MEFs: Mouse embryonic fibroblasts.

\section{Supplementary Material}

Supplementary table.

https://www.ijbs.com/v18p0956s1.pdf

\section{Acknowledgements}

This work was supported by grants from the National Key R\&D Program of China (2018YFA0800800 to DM), the National Natural Science Foundation of China (81730066 and 81230009 to D.M., 81600697 to W.J and 81701495 to Z.J.) and the Canadian Institutes of Health Research (PJT-152963 to DG).

\section{Author Contributions}

D.M. and D.G. conceived the project. J.W. and R.W. performed most of the experiments, analyzed and compiled the data. X.K., J.Z. and W.S. helped with experiments. J.W., D.M. and D.G. participated in writing or editing.

\section{Competing Interests}

The authors have declared that no competing interest exists.

\section{References}

1. Abbastabar M, Kheyrollah M, Azizian K, Bagherlou N, Tehrani SS, Maniati M, et al. Multiple functions of p27 in cell cycle, apoptosis, epigenetic modification and transcriptional regulation for the control of cell growth: A double-edged sword protein. DNA Repair (Amst). 2018; 69: 63-72.

2. Pippa R, Espinosa L, Gundem G, Garcia-Escudero R, Dominguez A, Orlando $\mathrm{S}$, et al. p27Kip1 represses transcription by direct interaction with p130/E2F4 at the promoters of target genes. Oncogene. 2012; 31: 4207-20.

3. Drissi H, Hushka D, Aslam F, Nguyen Q, Buffone E, Koff A, et al. The cell cycle regulator p27kip1 contributes to growth and differentiation of osteoblasts. Cancer research. 1999; 59: 3705-11.

4. Sun W, Wu J, Huang L, Liu H, Wang R, Karaplis A, et al. PTHrP Nuclear Localization and Carboxyl Terminus Sequences Modulate Dental and Mandibular Development in Part via the Action of p27. Endocrinology. 2016; 157: 1372-84.

5. Zhu M, Zhang J, Dong Z, Zhang Y, Wang R, Karaplis A, et al. The p27 Pathway Modulates the Regulation of Skeletal Growth and Osteoblastic Bone Formation by Parathyroid Hormone-Related Peptide. Journal of bone and mineral research : the official journal of the American Society for Bone and Mineral Research. 2015; 30: 1969-79.

6. van Lohuizen M, Verbeek S, Scheijen B, Wientjens E, van der Gulden H, Berns A. Identification of cooperating oncogenes in E mu-myc transgenic mice by provirus tagging. Cell. 1991; 65: 737-52.
7. Molofsky AV, Pardal R, Iwashita T, Park IK, Clarke MF, Morrison SJ. Bmi-1 dependence distinguishes neural stem cell self-renewal from progenitor proliferation. Nature. 2003; 425: 962-7.

8. Park I, Qian D, Kiel M, Becker MW, Pihalja M, Weissman IL, et al. Bmi-1 is required for maintenance of adult self-renewing haematopoietic stem cells. Nature. 2003; 423: 302-5.

9. van der Lugt NM, Domen J, Linders K, van Roon M, Robanus-Maandag E, te Riele $\mathrm{H}$, et al. Posterior transformation, neurological abnormalities, and severe hematopoietic defects in mice with a targeted deletion of the bmi-1 proto-oncogene. Genes Dev. 1994; 8: 757-69.

10. Zhang HW, Ding J, Jin JL, Guo J, Liu JN, Karaplis A, et al. Defects in mesenchymal stem cell self-renewal and cell fate determination lead to an osteopenic phenotype in Bmi-1 null mice. Journal of bone and mineral research : the official journal of the American Society for Bone and Mineral Research. 2010; 25: 640-52.

11. Sun H, Qiao W, Cui M, Yang C, Wang R, Goltzman D, et al. The Polycomb Protein Bmi1 Plays a Crucial Role in the Prevention of $1,25(\mathrm{OH}) 2$ D Deficiency-Induced Bone Loss. Journal of bone and mineral research : the official journal of the American Society for Bone and Mineral Research. 2020; 35: 583-95.

12. Wang X, Venugopal C, Manoranjan B, McFarlane N, O'Farrell E, Nolte S, et al. Sonic hedgehog regulates $\mathrm{Bmi1}$ in human medulloblastoma brain tumor-initiating cells. Oncogene. 2012; 31: 187-99.

13. Shahi $\mathrm{MH}$, Farheen S, Mariyath MP, Castresana JS. Potential role of Shh-Gli1-BMI1 signaling pathway nexus in glioma chemoresistance. Tumour Biol. 2016; 37: 15107-14

14. Zhu J, Nakamura E, Nguyen MT, Bao X, Akiyama H, Mackem S. Uncoupling Sonic hedgehog control of pattern and expansion of the developing limb bud. Dev Cell. 2008; 14: 624-32.

15. Takebe H, Shalehin N, Hosoya A, Shimo T, Irie K. Sonic Hedgehog Regulates Bone Fracture Healing. Int J Mol Sci. 2020; 21.

16. Cai JQ, Huang YZ, Chen XH, Xie HL, Zhu HM, Tang L, et al. Sonic hedgehog enhances the proliferation and osteogenic differentiation of bone marrow-derived mesenchymal stem cells. Cell Biol Int. 2012; 36: 349-55.

17. Huang C, Tang M, Yehling E, Zhang X. Overexpressing sonic hedgehog peptide restores periosteal bone formation in a murine bone allograft transplantation model. Mol Ther. 2014; 22: 430-9.

18. Shi S, Sun J, Meng $\mathrm{Q}, \mathrm{Yu}$ Y, Huang $\mathrm{H}$, Ma T, et al. Sonic hedgehog promotes endothelial differentiation of bone marrow mesenchymal stem cells via VEGF-D. J Thorac Dis. 2018; 10: 5476-88.

19. Bhatia B, Malik A, Fernandez LA, Kenney AM. p27(Kip1), a double-edged sword in Shh-mediated medulloblastoma: Tumor accelerator and suppressor. Cell Cycle. 2010; 9: 4307-14

20. Agarwal C, Dhanalakshmi S, Singh RP, Agarwal R. Inositol hexaphosphate inhibits growth and induces G1 arrest and apoptotic death of androgen-dependent human prostate carcinoma LNCaP cells. Neoplasia (New York, NY). 2004; 6: 646-59.

21. Li H, Collado M, Villasante A, Matheu A, Lynch CJ, Canamero M, et al. p27(Kip1) directly represses Sox2 during embryonic stem cell differentiation. Cell stem cell. 2012; 11: 845-52.

22. Orlando S, Gallastegui E, Besson A, Abril G, Aligue R, Pujol MJ, et al. p27Kip1 and p21Cip1 collaborate in the regulation of transcription by recruiting cyclin-Cdk complexes on the promoters of target genes. Nucleic acids research. 2015; 43: 6860-73.

23. Perearnau A, Orlando S, Islam A, Gallastegui E, Martinez J, Jordan A, et al. p27Kip1, PCAF and PAX5 cooperate in the transcriptional regulation of specific target genes. eLife. 2017; 45: 5086-99.

24. Yin $Y$, Xue $X$, Wang $Q$, Chen N, Miao D. Bmi1 plays an important role in dentin and mandible homeostasis by maintaining redox balance. American journal of translational research. 2016; 8: 4716-25.

25. Miao D, Bai X, Panda D, McKee M, Karaplis A, Goltzman D. Osteomalacia in hyp mice is associated with abnormal phex expression and with altered bone matrix protein expression and deposition. Endocrinology. 2001; 142: 926-39.

26. Xue Y, Zhang Z, Karaplis AC, Hendy GN, Goltzman D, Miao D. Exogenous PTH-related protein and PTH improve mineral and skeletal status in 25-hydroxyvitamin D-1alpha-hydroxylase and PTH double knockout mice. Journal of bone and mineral research : the official journal of the American Society for Bone and Mineral Research. 2005; 20: 1766-77.

27. Miao D, Scutt A. Histochemical localization of alkaline phosphatase activity in decalcified bone and cartilage. J Histochem Cytochem. 2002; 50: 333-40.

28. Yang R, Chen J, Zhang J, Qin R, Wang R, Qiu Y, et al. 1,25-Dihydroxyvitamin $\mathrm{D}$ protects against age-related osteoporosis by a novel VDR-Ezh2-p16 signal axis. Aging Cell. 2020; 19: e13095.

29. Haghighat N, Abdolmaleki P, Parnian J, Behmanesh M. The expression of pluripotency and neuronal differentiation markers under the influence of electromagnetic field and nitric oxide. Mol Cell Neurosci. 2017; 85: 19-28.

30. Miao D, He B, Lanske B, Bai XY, Tong XK, Hendy GN, et al. Skeletal abnormalities in Pth-null mice are influenced by dietary calcium. Endocrinology. 2004; 145: 2046-53.

31. Liu J, Lv F, Sun W, Tao C, Ding G, Karaplis A, et al. The abnormal phenotypes of cartilage and bone in calcium-sensing receptor deficient mice are dependent on the actions of calcium, phosphorus, and PTH. PLoS Genet. 2011; 7: e1002294. 
32. Kuleshov MV, Jones MR, Rouillard AD, Fernandez NF, Duan Q, Wang Z, et al. Enrichr: a comprehensive gene set enrichment analysis web server 2016 update. Nucleic acids research. 2016; 44: W90-7.

33. Chu IM, Hengst L, Slingerland JM. The Cdk inhibitor p27 in human cancer: prognostic potential and relevance to anticancer therapy. Nat Rev Cancer. 2008; 8: 253-67.

34. Yang J, Andre P, Ye L, Yang YZ. The Hedgehog signalling pathway in bone formation. Int J Oral Sci. 2015; 7: 73-9.

35. Kitaura Y, Hojo H, Komiyama Y, Takato T, Chung UI, Ohba S. Gli1 haploinsufficiency leads to decreased bone mass with an uncoupling of bone metabolism in adult mice. PloS one. 2014; 9: e109597.

36. Miao D, Liu H, Plut P, Niu M, Huo R, Goltzman D, et al. Impaired endochondral bone development and osteopenia in Gli2-deficient mice. Experimental cell research. 2004; 294: 210-22.

37. Ohba S, Kawaguchi H, Kugimiya F, Ogasawara T, Kawamura N, Saito T, et al. Patched1 haploinsufficiency increases adult bone mass and modulates Gli3 repressor activity. Dev Cell. 2008; 14: 689-99.

38. Svard J, Heby-Henricson K, Persson-Lek M, Rozell B, Lauth M, Bergstrom A, et al. Genetic elimination of Suppressor of fused reveals an essential repressor function in the mammalian Hedgehog signaling pathway. Dev Cell. 2006; 10: 187-97.

39. Rice DP, Connor EC, Veltmaat JM, Lana-Elola E, Veistinen L, Tanimoto Y, et al. Gli3Xt-J/Xt-J mice exhibit lambdoid suture craniosynostosis which results from altered osteoprogenitor proliferation and differentiation. Hum Mol Genet. 2010; 19: 3457-67.

40. Aditya S, Rattan A. Vismodegib: A smoothened inhibitor for the treatment of advanced basal cell carcinoma. Indian Dermatol Online J. 2013; 4: 365-8.

41. Hu Z, Chen B, Zhao Q. Hedgehog signaling regulates osteoblast differentiation in zebrafish larvae through modulation of autophagy. Biol Open. 2019; 8 .

42. Anna V M, Ricardo P, Toshihide I, In-Kyung P, Michael F C, Sean J M. Bmi-1 dependence distinguishes neural stem cell self-renewal from progenitor proliferation. Nature. 2003; 425: 962-7.

43. In-Kyung P, Dalong $\mathrm{Q}$, Mark K, Becker MW, Michael P, Weissman IL, et al. Bmi-1 is required for maintenance of adult self-renewing haematopoietic stem cells. Nature. 2003; 423: 302-5.

44. Liu J, Cao L, Chen J, Song S, Lee IH, Quijano C, et al. Bmi1 regulates mitochondrial function and the DNA damage response pathway. Nature. 2009; 459: 387

45. Leung C, Lingbeek M, Shakhova O, Liu J, Tanger E, Saremaslani P, et al. Bmi1 is essential for cerebellar development and is overexpressed in human medulloblastomas. Nature. 2004; 428: 337-41.

46. Liu S, Dontu G, Mantle ID, Patel S, Ahn NS, Jackson KW, et al. Hedgehog signaling and Bmi-1 regulate self-renewal of normal and malignant human mammary stem cells. Cancer research. 2006; 66: 6063-71. 